\title{
The C-Terminal Sequence of Several Human Serine Proteases Encodes Host Defense Functions
}

\author{
Gopinath Kasetty ${ }^{a}$ Praveen Papareddy ${ }^{a}$ Martina Kalle ${ }^{a}$ Victoria Rydengård $^{a}$ \\ Björn Walse $^{c}$ Bo Svensson ${ }^{c}$ Matthias Mörgelin ${ }^{b}$ Martin Malmsten $^{d}$ \\ Artur Schmidtchen ${ }^{a}$ \\ Divisions of ${ }^{\mathrm{a}}$ Dermatology and Venereology and ${ }^{\mathrm{b}}$ Infection Medicine, Department of Clinical Sciences, \\ Lund University, Biomedical Center, and 'SARomics AB, Lund, and d Department of Pharmacy, Uppsala University, \\ Uppsala, Sweden
}

\section{Key Words}

Antimicrobial peptide $\cdot$ Coagulation $\cdot$ Host defense $\cdot$

Endotoxin - Proteinase

\section{Abstract}

Serine proteases of the S1 family have maintained a common structure over an evolutionary span of more than one billion years, and evolved a variety of substrate specificities and diverse biological roles, involving digestion and degradation, blood clotting, fibrinolysis and epithelial homeostasis. We here show that a wide range of C-terminal peptide sequences of serine proteases, particularly from the coagulation and kallikrein systems, share characteristics common with classical antimicrobial peptides of innate immunity. Under physiological conditions, these peptides exert antimicrobial effects as well as immunomodulatory functions by inhibiting macrophage responses to bacterial lipopolysaccharide. In mice, selected peptides are protective against lipopolysaccharide-induced shock. Moreover, these S1-derived host defense peptides exhibit helical structures upon binding to lipopolysaccharide and also permeabilize liposomes. The re- sults uncover new and fundamental aspects on host defense functions of serine proteases present particularly in blood and epithelia, and provide tools for the identification of host defense molecules of therapeutic interest.

Copyright $\odot 2011$ S. Karger AG, Basel

\section{Introduction}

The innate immune system provides a first line of defense against invading microbes [1-5]. Its effectors, such as the classic antimicrobial peptides defensins and cathelicidins, exert direct bactericidal effects, but also mediate various immunomodulatory functions including antiendotoxic effects, chemotaxis and angiogenesis [6-8], thus motivating the broader definition of host defense peptides (HDPs) for these members of the innate immune system. The recent discovery that C-terminal peptides of human thrombin, a key enzyme in the coagulation cascade, constitute a novel class of HDPs with bactericidal and anti-inflammatory properties, has defined new HDPs and expanded the field of innate immunity to

\section{KARGER \\ Fax +4161306 1234 \\ E-Mail karger@karger.ch}

www.karger.com
(C) 2011 S. Karger AG, Basel

$1662-811 X / 11 / 0035-0471 \$ 38.00 / 0$

Accessible online at:

www.karger.com/jin
Dr. Artur Schmidtchen

Division of Dermatology and Venereology, Department of Clinical Sciences

Lund University, Biomedical Center, Tornavägen 10

SE-22184 Lund (Sweden)

Tel. +46 46222 4522, E-Mail artur.schmidtchen@med.lu.se 
thrombin and the coagulation system [9]. From an evolutionary perspective, this additional role of thrombin is logical, since injury and infection both represent situations necessitating an optimized innate immune system $[10,11]$. Structurally, analyses show that the major thrombin-derived C-terminal peptide of 96 amino acids represents a novel structural entity, which is related to other cysteine-linked HDPs, including defensins, containing the $\gamma$-core motif $[9,12]$.

During the course of these studies, we noted that C terminals of thrombin, as well as other related coagulation factors, comply with a pattern sequence X-[PFY]-X[AFILV]-[AFY]-[AITV]-X-[ILV]-X(5)-W-[IL]-X $(5,26)$ (PROSITE pattern [13]) found not only in these proteases of the coagulation system, but also present in the vast and diverse family of $\mathrm{S} 1$ peptidases. The observation that this C-terminal sequence contains interspersed conserved hydrophobic residues, which, given an $\alpha$-helical conformation (characterizing all structurally determined S1 peptidases), consequently describe a potential amphipathic structure, prompted us to investigate whether the concept of HDPs of coagulation factors could be extended to the family of S1 peptidases.

\section{Materials and Methods}

\section{Peptides}

The S1-derived peptides described in figure 4 were synthesized by Biopeptide Co. The purity (>95\%) of these peptides was confirmed by mass spectral analysis (MALDI.TOF Voyager). 20 mer peptides described in figures 1 and 2 as well as online supplementary figure 1 (www.karger.com/doi/10.1159/000327016) were from Sigma (Custom Peptide Libraries; Sigma Genosys).

\section{Microorganisms}

Escherichia coli ATCC 25922, Pseudomonas aeruginosa ATCC 27853, Staphylococcus aureus ATCC 29213, and the fungal isolate Candida albicans ATCC 90028 were originally from ATCC. P. aeruginosa 15159 was a clinical isolate derived from a patient with a chronic venous leg ulcer [14].

\section{Radial Diffusion Assay}

Essentially as described earlier $[15,16]$, bacteria were grown to mid-logarithmic phase in $10 \mathrm{ml}$ of full-strength $(3 \% \mathrm{w} / \mathrm{v})$ trypticase soy broth (TSB; Becton-Dickinson). The microorganisms were then washed once with $10 \mathrm{mM}$ Tris, $\mathrm{pH}$ 7.4. Subsequently, 4 $\times 10^{6} \mathrm{CFU}$ were added to $15 \mathrm{ml}$ of the underlay agarose gel, consisting of $0.03 \%(\mathrm{w} / \mathrm{v}) \mathrm{TSB}, 1 \%(\mathrm{w} / \mathrm{v})$ low electroendosmosis type agarose (Sigma-Aldrich) and $0.02 \%$ (v/v) Tween 20 (Sigma-Aldrich). The underlay was poured into a $144-\mathrm{mm}$ diameter petri dish. After agarose solidification, 4-mm diameter wells were punched and $6 \mu$ l peptide solution of required concentration added to each well. Plates were incubated at $37^{\circ} \mathrm{C}$ for $3 \mathrm{~h}$ to allow peptide diffusion. The underlay gel was then covered with $15 \mathrm{ml}$ of molten overlay (6\% TSB and $1 \%$ low electroendosmosis type agarose in distilled $\mathrm{H}_{2} \mathrm{O}$ ). Antimicrobial activity of a peptide was visualized as a zone of clearing around each well after $18-24 \mathrm{~h}$ of incubation at $37^{\circ} \mathrm{C}$.

\section{Viable Count Analysis}

E. coli strains were grown to mid-logarithmic phase in ToddHewitt (TH) medium. $P$. aeruginosa strains were grown in $\mathrm{TH}$ overnight. Bacteria were washed and diluted in $10 \mathrm{~mm}$ Tris, $\mathrm{pH}$ 7.4 , containing $5 \mathrm{mM}$ glucose containing $0.15 \mathrm{M} \mathrm{NaCl}$, alone or with $20 \%$ normal citrate plasma. $2 \times 10^{6} \mathrm{CFU} / \mathrm{ml}$ bacteria were incubated in $50 \mu \mathrm{l}$, at $37^{\circ} \mathrm{C}$ for $2 \mathrm{~h}$, with the S1-derived peptides at the indicated concentrations. Serial dilutions of the incubation mixture were plated on $\mathrm{TH}$ agar, followed by incubation at $37^{\circ} \mathrm{C}$ overnight and CFU determination.

\section{LPS and Zymosan Effects on Macrophages in vitro}

$3.5 \times 10^{5}$ RAW264.7 macrophage cells were seeded in 96-well tissue culture plates (167008; Nunc) in phenol red-free DMEM (Gibco) supplemented with 10\% FBS containing 1\% Anti-Anti (Invitrogen). Following $20 \mathrm{~h}$ of incubation to permit adherence, cells were washed and stimulated with either $10 \mathrm{ng} / \mathrm{ml}$ LPS (E. coli 0111:B4; Sigma) or $25 \mu \mathrm{g} / \mathrm{ml}$ zymosan (Saccharomyces cerevisiae; Sigma), with and without the S1-derived peptides of various doses. The levels of NO in culture supernatants were determined after $24 \mathrm{~h}$ from stimulation using the Griess reaction [17]. Briefly, nitrite, a stable product of NO degradation, was measured by mixing $50 \mu \mathrm{l}$ of culture supernatants with the same volume of Griess reagent (G4410; Sigma) and reading absorbance at $550 \mathrm{~nm}$ after 15 min. Phenol red-free DMEM with FBS and antibiotics were used as a blank. A standard curve was prepared using $0-80 \mu \mathrm{M}$ sodium nitrite solutions in ddH20.

\section{LPS Model in vivo}

Male C57BL/6 mice (8-10 weeks, $22 \pm 5 \mathrm{~g}$ ), were injected intraperitoneally with $18 \mathrm{mg}$ E. coli 0111:B4 LPS (Sigma) per kilogram of body weight. Thirty minutes after LPS injection, $0.5 \mathrm{mg}$ of the indicated S1-peptides or buffer alone was injected intraperitoneally into the mice. Survival and status were followed for 7 days. For blood collection and histochemistry, mice were sacrificed $20 \mathrm{~h}$ after LPS challenge, and lungs were removed and fixed. These experiments were approved by the Laboratory Animal Ethics Committee of Malmö/Lund.

\section{Tissue Analyses}

For scanning electron microscopy, specimens were washed with cacodylate buffer, and dehydrated with an ascending ethanol series from $50 \%(\mathrm{v} / \mathrm{v})$ to absolute ethanol (10 min per step). The specimens were then subjected to critical-point drying in carbon dioxide, with absolute ethanol as intermediate solvent, mounted on aluminium holders, sputtered with $30 \mathrm{~nm}$ palladium/gold, and examined in a JEOL JSM-350 scanning electron microscope. For histological evaluation of lungs derived from the in vivo LPS models in mice, tissues were embedded as above, sectioned and stained with hematoxylin and eosin by routine procedures (Histocenter).

\section{Cytokine Assay}

The cytokines IL- 6 , IL-10, MCP-1, INF- $\gamma$ and TNF- $\alpha$ were measured in plasma from mice subjected to LPS (with or without 


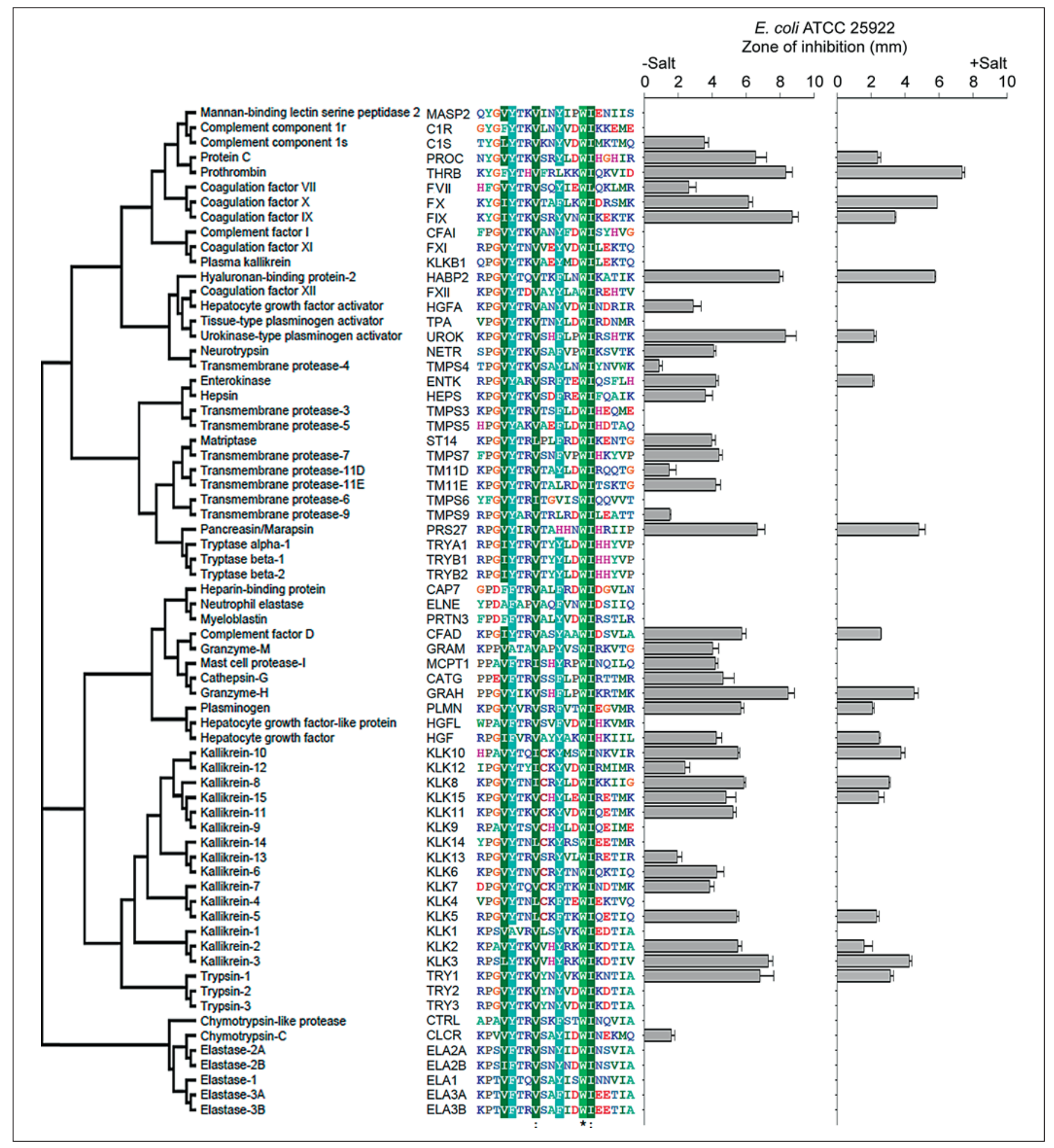

Fig. 1. Activities of S1-derived peptides comprising the pattern sequence X-[PFY]-X-[AFILV]-[AFY]-[AITV]-X-[ILV]-X(5)-W-[IL]$\mathrm{X}(5,26)$. Protein names (with abbreviations), the respective peptide sequences and antimicrobial activity against E. coli ATCC 25922 in $10 \mathrm{mM}$ Tris buffer (with or without additional $0.15 \mathrm{M}$ $\mathrm{NaCl}$ ) are indicated. For determination of antimicrobial activi- ties, E. coli $\left(4 \times 10^{6} \mathrm{CFU}\right)$ was inoculated in $0.1 \%$ TSB agarose gel. Each $4-\mathrm{mm}$ diameter well was loaded with $6 \mu \mathrm{l}$ of peptide (at 100 $\mu \mathrm{M})$. The zones of clearance (in millimeters) correspond to the inhibitory effect of each peptide after incubation at $37^{\circ} \mathrm{C}$ for 18 $24 \mathrm{~h}$ (mean values are presented, $\mathrm{n}=3$ ). A control with buffer only yielded no inhibition zone. 


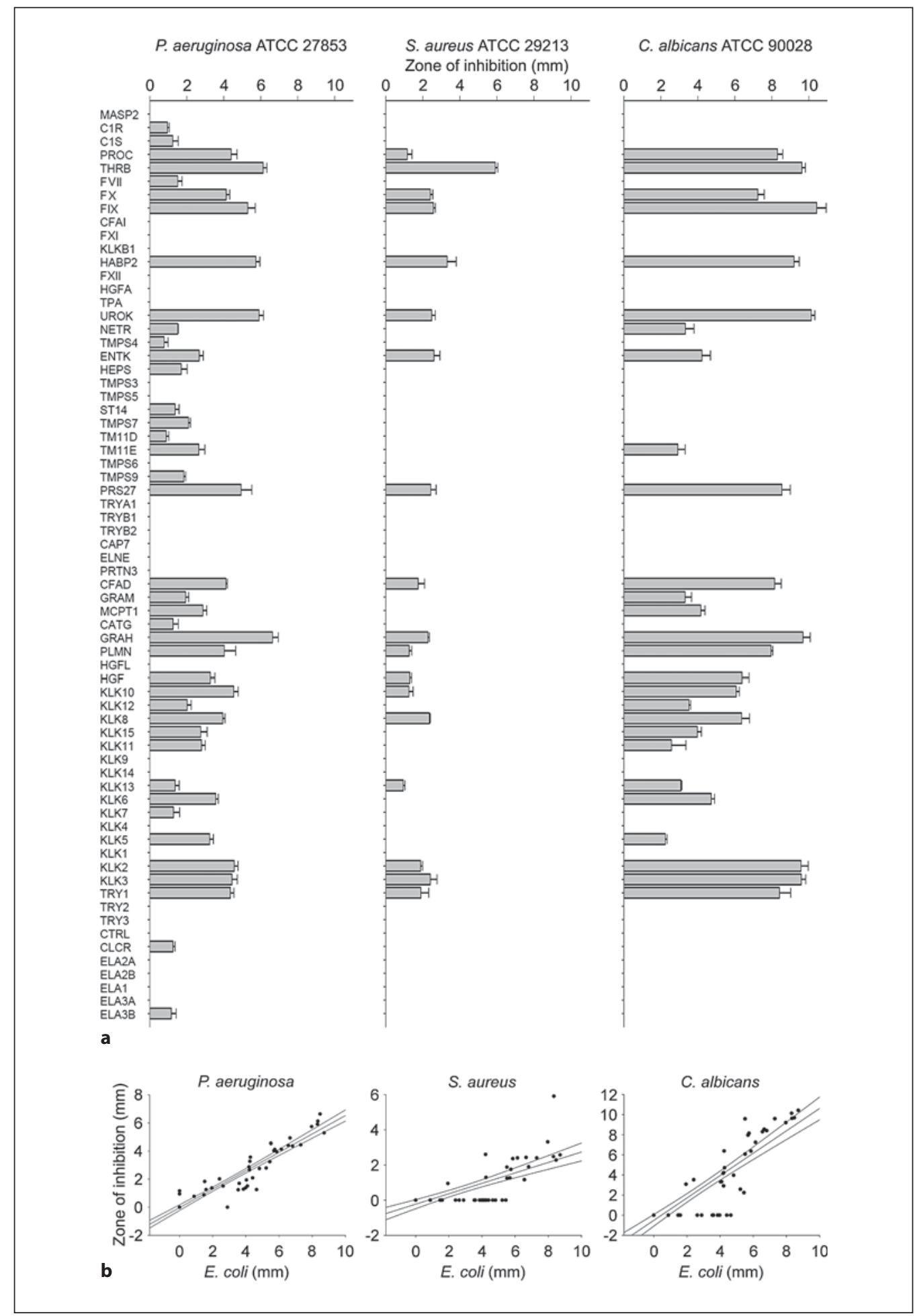

Fig. 2. Activities of S1-derived peptides against $P$. aeruginosa, $S$. aureus and C. albicans. a For determination of antimicrobial activities, P. aeruginosa ATCC 27853, S. aureus ATCC $29213(4 \times$ $10^{6} \mathrm{CFU}$ for both) and C. albicans ATCC $90028\left(1 \times 10^{5} \mathrm{CFU}\right)$ were inoculated in $0.1 \%$ TSB agarose gel. As in figure 1, each 4 -mm diameter well was loaded with $6 \mu$ l of peptide (at $100 \mu \mathrm{M}$ ).
The zones of clearance (in millimeters) correspond to the inhibitory effect of each peptide after incubation at $37^{\circ} \mathrm{C}$ for $18-24 \mathrm{~h}$ (mean values are presented, $\mathrm{n}=3$ ). A control with buffer only yielded no inhibition zone. $\mathbf{b}$ The graphs show the relation between the activity (zone of clearance, in millimeters) against $E$. coli (x-axis) and the respective microbes (y-axis). 
peptide treatment) using the cytometric bead array and mouse inflammation kit (Becton Dickinson $\mathrm{AB}$ ) according to the manufacturer's instructions.

\section{Phylogenetic Analyses of S1 Sequences}

The sequences for $\mathrm{S} 1$ peptidases were retrieved from the NCBI site. Each sequence was analyzed with Psi-Blast (NCBI) to find the ortholog and paralog sequences. Sequences that showed sequence homology $>70 \%$ were selected. These sequences were aligned using ClustalW using Blosum 69 protein weight matrix settings. Internal adjustments were made taking the structural alignment into account utilizing the ClustalW interface. The level of consistency of each position within the alignment was estimated by using the alignment-evaluating software Tcoffee.

\section{Liposome Preparation and Leakage Assay}

Dry lipid films were prepared by dissolving dioleoylphosphatidylethanolamine (70 mol\%; Avanti Polar Lipids) and dioleoylphosphatidylglycerol (30 mol\%) in chloroform, and then removing the solvent by evaporation under vacuum overnight. Subsequently, buffer solution containing $10 \mathrm{mM}$ Tris, $\mathrm{pH} 7.4$, was added together with $0.1 \mathrm{M}$ carboxyfluorescein (CF; Sigma). After hydration, the lipid mixture was subjected to 8 freeze-thaw cycles consisting of freezing in liquid nitrogen and heating to $60^{\circ} \mathrm{C}$. Unilamellar liposomes with a diameter of about $140 \mathrm{~nm}$ were generated by multiple extrusions through polycarbonate filters (pore size $100 \mathrm{~nm}$ ) mounted in a LipoFast miniextruder (Avestin). Untrapped CF was then removed by filtration through two subsequent Sephadex G-50 columns with the Tris buffer as eluent. Both extrusion and filtration were performed at $22^{\circ} \mathrm{C}$. The $\mathrm{CF}$ release was monitored by fluorescence at $520 \mathrm{~nm}$ from a liposome dispersion (10 $\mu \mathrm{M}$ lipid in $10 \mathrm{~mm}$ Tris, $\mathrm{pH}$ 7.4). An absolute leakage scale was obtained by disrupting the liposomes at the end of the experiment through addition of $0.8 \mathrm{mM}$ Triton X100 (Sigma), thereby causing $100 \%$ release and dequenching of CF. A SPEX-fluoro$\log 1650$ 0.22-m double spectrometer (SPEX Industries) was used for the liposome leakage assay. Measurements were performed in triplicate at $37^{\circ} \mathrm{C}$.

\section{Circular Dichroism Spectroscopy}

Circular dichroism spectra were recorded by a J-810 Spectropolarimeter (Jasco). The measurements were performed in triplicate at $37^{\circ} \mathrm{C}$ in a $10-\mathrm{mm}$ quartz cuvette under stirring with a peptide concentration of $10 \mu \mathrm{M}$. The effect on peptide secondary structure of liposomes at a lipid concentration of $100 \mu \mathrm{M}$, and of E. coli LPS at a concentration of $0.02 \mathrm{wt} \%$, was monitored in the range of 200-260 $\mathrm{nm}$. To account for instrumental differences between measurements, the background value (detected at 250 $\mathrm{nm}$, where no peptide signal is present) was subtracted. Signals from the bulk solution were also corrected for.

\section{Electron Microscopy}

For transmission electron microscopy and visualization of peptide effects on bacteria, P. aeruginosa ATCC 27853 and S. aureus ATCC 29213 (1-2 × $10^{6} \mathrm{CFU} /$ sample) were incubated for $2 \mathrm{~h}$ at $37^{\circ} \mathrm{C}$ with $\mathrm{S} 1$ peptides $(30 \mu \mathrm{M})$. Samples of $P$. aeruginosa and $S$. aureus suspensions were adsorbed onto carbon-coated copper grids for $2 \mathrm{~min}$, washed briefly by two drops of water, and negatively stained by two drops of $0.75 \%$ uranyl formate. The grids were rendered hydrophilic by glow discharge at low pressure in air. All samples were examined with a Jeol JEM 1230 electron microscope operated at $80 \mathrm{kV}$ accelerating voltage. Images were recorded with a Gatan Multiscan 791 charge-coupled device camera.

Quantitative Structure Activity Relationship Analysis

The E. coli antimicrobial activity and the LPS-blocking activity were subjected to a quantitative structure activity relationship (QSAR) analysis [18]. The QSAR methodology has a long tradition within the field of drug design, hence technical details can be found elsewhere. In short, computed properties (descriptors) of the peptides were correlated with the particular experimental property of interest (the E. coli antimicrobial activity or LPS inhibition). The partial least squares regression (PLS) method was used to obtain the relationship

$$
\mathrm{Y}=\mathrm{C}_{0}+\mathrm{C}_{1} \cdot \mathrm{X}_{1}+\mathrm{C}_{2} \cdot \mathrm{X}_{2}+\ldots+\mathrm{C}_{\mathrm{N}} \cdot \mathrm{X}_{\mathrm{N}}
$$

where $\mathrm{C}$ are constants, $\mathrm{X}$ are peptide descriptors and $\mathrm{Y}$ is the property of interest. A large number of peptide descriptors were computed with the software ProPHECY ${ }^{\mathrm{TM}}$ (http://www.saromics. $\mathrm{com} /$ Technologies/Technologies.html). The number of PLS components was determined by means of cross-validation. The E. coli model was based on the first set (fig. 1) of peptides only. This model was used to predict the properties of the second set (online suppl. fig. 1) of peptides. Thus, the second set of peptides could be regarded as a test set as it had no influence on the developed QSAR model. The most important descriptor of the model was the peptide net charge, while other less important descriptors were related to the hydrophobicity as well as electrostatic and hydrophobic moments. Despite that all except 4 peptides in the first set of peptides showed little effect on LPS inhibition, peptides could be partitioned into two groups: those with little and those with strong effects on LPS inhibition. Using the PLS method, a model was defined that correctly separated the peptides into the two categories. The 4 peptides with high effect on LPS blocking also clustered in the same region of the score plot. A number of both simple and complex electrostatics- and hydrophobicity-related descriptors contributed to the QSAR model. This model was then used to compute the scores for the second set of peptides. Although as little as 4 peptides in the training set had large effect on LPS inhibition, the QSAR model appeared to have predictive value. There was only 1 peptide in the second set with a high effect on LPS inhibition, and this was correctly suggested by the model. Furthermore, all except 2 peptides of the second set were correctly predicted as having little LPS effect (online suppl. fig. 1).

\section{Results}

\section{Initial Characterization of Antimicrobial Effects}

The application of the pattern sequence X-[PFY]-X[AFILV]-[AFY]-[AITV]-X-[ILV]-X(5)-W-[IL]-X(5,26) described above captured 68 S1 peptide sequences, which were synthesized and screened for antimicrobial effects against the Gram-negative bacterium E. coli. In a first screening round, the results indeed showed that a significant proportion of the sequences, here grouped accord- 


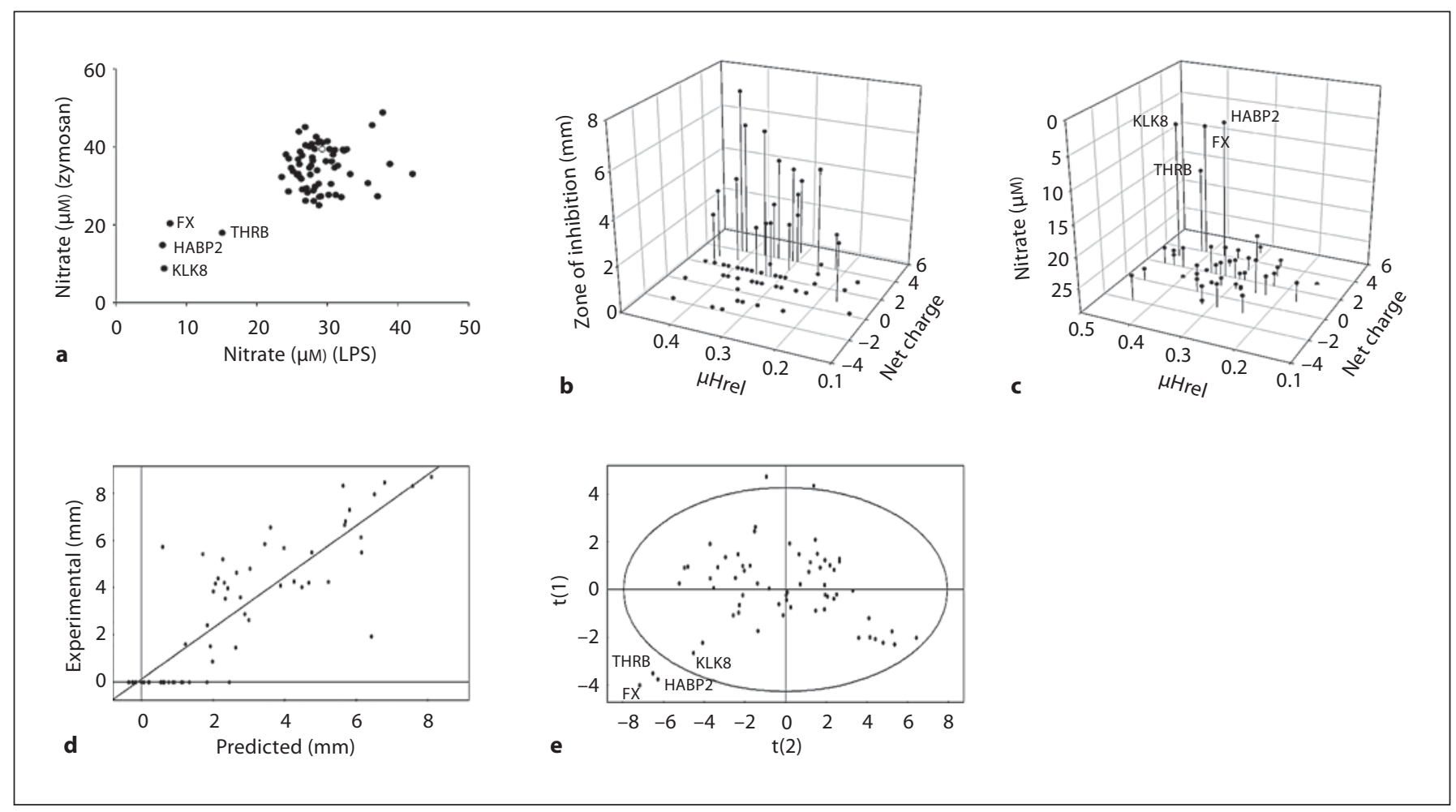

Fig. 3. Immunomodulatory effects of peptides and structurefunction analyses. a Effects of S1-derived peptides on NO production by macrophages. RAW264.7 mouse macrophages were incubated with LPS from E. coli or zymosan from S. cerevisiae in presence of S1-peptides at $10 \mu \mathrm{M}$. NO production in the culture media $24 \mathrm{~h}$ after the treatment was determined using the Griess reagent. The indicated 4 peptides significantly blocked NO responses (mean values are presented, $\mathrm{n}=3$ ). A representative experiment (of 3) is shown. The open circle shows negative control. b Structure-function analyses on S1-derived peptides. Graph illustrating the relation between inhibitory zones in RDA, relative hydrophobic moment $(\mu \mathrm{Hrel})$ and net charge of respective S1-peptides. E. coli data are presented and the salt strength was $0.15 \mathrm{M} \mathrm{NaCl}$. c Graph illustrating the correspondence to NO-blocking activity. Active peptides are indicated in the three-dimensional graph. d QSAR model for the experimental versus predicted values for the set of S1-peptides with respect to antimicrobial activity against E. coli. E. coli, $\mathrm{r}^{2}=0.73$ and $\mathrm{q}^{2}=0.63$. e Scatter plot based on a PLS-model for LPS-blocking activity. ing to an evolutionary tree generated for the protease domain [19], displayed antimicrobial activities in low as well as physiological salt conditions (fig. 1). In line with previous results, peptides derived from coagulation factors II (thrombin), IX and X were particularly active [9], demonstrating retained effects in $0.15 \mathrm{M} \mathrm{NaCl}$, an indicator of potential effects at physiological conditions. Additional peptides showing activity in $0.15 \mathrm{M} \mathrm{NaCl}$ comprised sequences from the plasma-derived peptidases HABP2, protein $\mathrm{C}$, plasminogen as well as several epithelial-derived peptidases of the kallikrein family. Further analyses of effects on the Gram-negative P. aeruginosa, the Grampositive $S$. aureus and the fungus $C$. albicans demonstrated a broad-spectrum activity of the peptides (fig. 2a). A significant correlation, particularly between the killing of E. coli and effects on P. aeruginosa and C. albicans, was noted, and a subset of the peptides was also active against S. aureus (fig. 2b).

\section{Immunomodulatory Effects, Biophysical Parameters and Activity Predictions}

As mentioned above, recent evidence shows that HDPs may trigger a range of immunomodulatory responses. In a mouse macrophage model (and using $10 \mu \mathrm{M}$ of peptide), 4 of the peptides significantly inhibited NO release of LPS-as well as zymosan-stimulated macrophages (fig. 3a). Although the underlying mechanisms clearly need to be investigated further, the results suggest that these peptides may affect TLR-4- [20] and dectin-1-mediated [21] responses, respectively. Properties common for most an- 
timicrobial peptides include minimum levels of cationicity, amphipathicity and hydrophobicity [1-5], and consequently peptides characterized by a high relative hydrophobicity ( $\mu \mathrm{Hrel}$ ) and a positive net charge (for example $z_{\text {net }} \geq+2$ ) retained their antimicrobial activity against $E$. coli at physiologic conditions (fig. 3b). A similar but even more marked correspondence was observed for the antiendotoxic activity (fig. 3c). QSAR models [22] based on the data for peptides 1-68 were developed for the antimicrobial effect on E. coli, as well as peptide-induced NO blocking (fig. 3d, e). As seen, a correspondence between the observed and predicted antimicrobial activities was noted, and notably, a scatter plot defining NO-blocking activity on LPS-stimulated macrophages clustered peptides of high inhibitory activity. Evaluation of the QSAR parameters showed that a number of descriptors significantly contributed to the model, including net charge and hydrophobicity, as well as additional complex descriptors comprising electrostatic and hydrophobic components, which further refined the analysis (see Materials and Methods). Finally, additional peptide sequences not included in the first dataset (deposited during the course of the study), as well as sequences identified by a variant pattern sequence capturing almost all members belonging to the S1 peptidase family, X-[GFPRY]-X-[AFILVY][ACFHITY]-[AGILSTV]-[ADHKLNQRSY]-[ILSTV]$\{\mathrm{R}\}-\mathrm{X}(4)-\mathrm{W}$-[ILV]-X(3)-[AILMTVW]-X(1,48), were analyzed (online suppl. fig. 1a). In general, utilizing the above biophysical and QSAR data, the predicted antimicrobial effects were in good agreement with the observed antimicrobial activities (online suppl. fig. 1b), and in the case of a granzyme B-derived peptide, the predicted antiendotoxic effect also agreed with the observed activity (online suppl. fig. 1c).

\section{Analysis of Antimicrobial and Immunomodulatory}

Activities at Physiological Conditions

In order to further validate and extend the above findings into a relevant physiologic environment, highly purified HDPs, all meeting the following criteria: $\mu$ Hrel $>0.4, z_{n e t} \geq+2$ and bactericidal activity in $0.15 \mathrm{M} \mathrm{NaCl}$, were synthesized and analyzed in matrix-free viable count assays in the presence of salt and human plasma (fig. $4 \mathrm{a}, \mathrm{b}$ ). The results demonstrated that in contrast to the control peptides from FXI, C1r and kallikrein 9, peptides derived from the coagulation system-related proteins thrombin, factors IX and $\mathrm{X}$, plasminogen, protein $\mathrm{C}$, the plasma proteins ApoA and HABP2, the cytotoxic T cell-associated granzyme $\mathrm{B}$ and $\mathrm{H}$ as well as epithelialassociated kallikreins 5, 8 and 10, all demonstrated sig- nificant antibacterial activity (fig. 4a), thus corroborating the above RDA screening assays. Furthermore, in concordance with previous results, as well as predictions, peptides from thrombin, FX, HABP2, kallikrein 8 and granzyme B were particularly antiendotoxic at 5-10 $\mu \mathrm{M}$ (fig. $4 \mathrm{~b}$ ), although it was noted that other peptides also inhibited the LPS effects at concentrations exceeding the initially used screening dose of $10 \mu \mathrm{M}$. The color-coding illustrates the product of relative hydrophobicity and net charge, two major parameters determining AMP activity $[12,22,23]$.

\section{Peptide Effects in Animal Models of LPS-Mediated Shock}

The above observations prompted us to investigate the above peptides' immunomodulatory capacity in vivo. In a mouse model of LPS-induced shock, selected peptides from thrombin, FX, HABP2 and kallikrein 8 displayed a dramatic improvement on survival (fig. 4c), in parallel with animal weight recovery (online suppl. fig. 2). Analyses of cytokines $20 \mathrm{~h}$ after LPS injection showed significant reductions of pro-inflammatory IL- 6 , IFN- $\gamma$, TNF$\alpha$ and MCP-1, whereas anti-inflammatory IL-10 was increased (fig. 4d). Histological and scanning electron microscopy analyses of lungs from LPS-treated animals demonstrated significant pulmonary leakage of protein and red blood cells (fig. 4e), an effect completely blocked by the above peptides. In contrast, the control peptide from FXI showed no effects in these models. The results thus demonstrate a possible therapeutic potential of these novel S1-derived HDPs in settings of inflammation and endotoxic shock.

\section{Structural Considerations and Mode of Action}

The models presented in figure 5 illustrate the cationicity as well as amphipathicity of the HDP sequences, situated in their holoproteins (fig. 5a), or as 20 -mers (fig. 5b). As seen, the peptides, including the nonactive FXI peptide, all show a helical structure when situated in their holoproteins, and conform to an amphipathic structure. Importantly however, only peptides acting as HDPs display an induced helical conformation in the presence of bacterial LPS (fig. 5c) as well as negatively charged (bacteria-like) liposomes (fig. 5d), and have the ability to permeabilize liposomes (fig. 5e). Therefore, they meet the primary prerequisite for AMPs of initial bacterial LPS interactions, facilitating subsequent bacterial permeabilization, as evidenced by transmission electron microscopy studies (fig. 5f), and/or anti-endotoxic effects in vitro and in vivo (fig. $4 \mathrm{~b}-\mathrm{e}$ ). At the structural level, high activity 


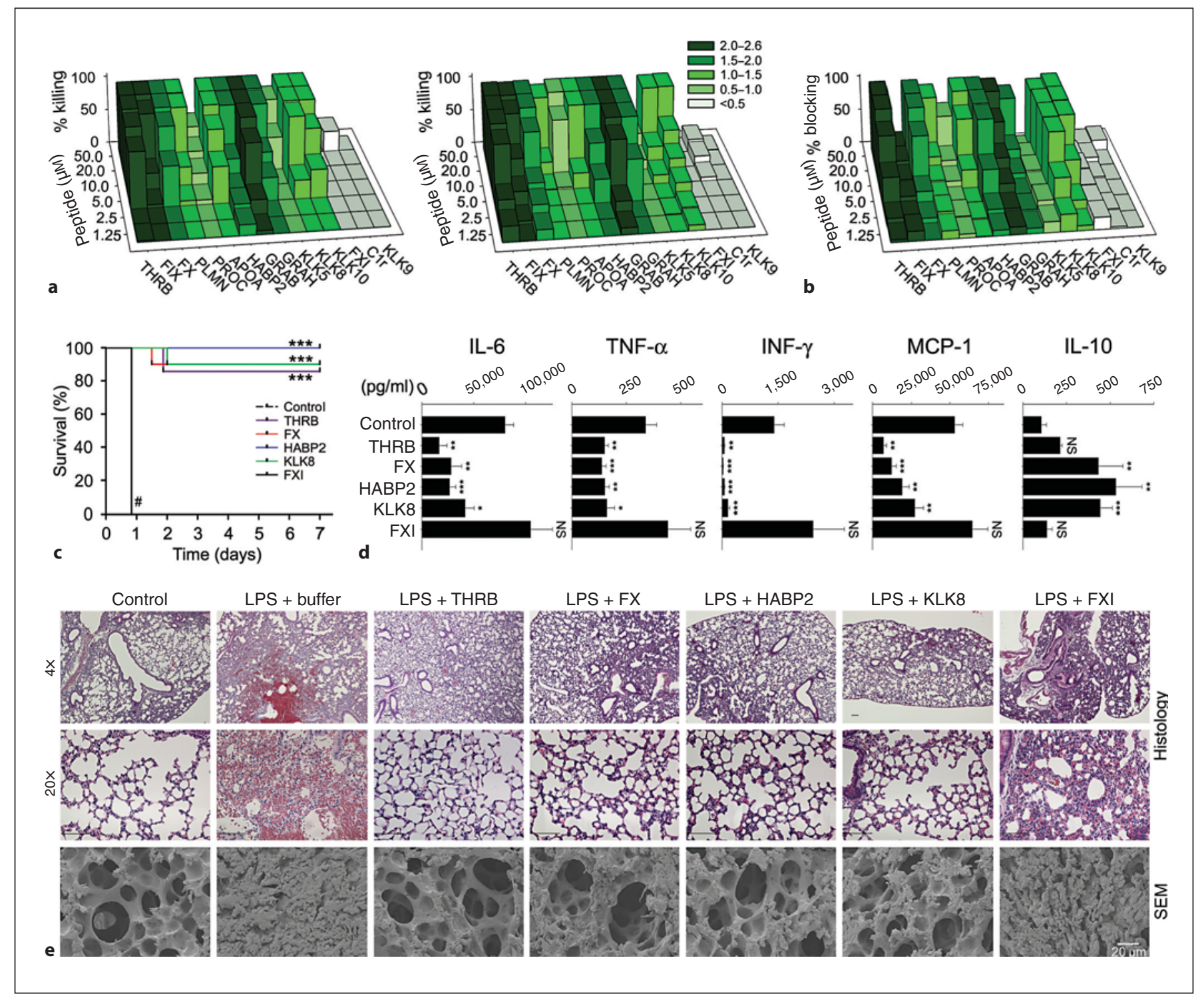

Fig. 4. In vitro and in vivo analyses of peptide effects. a Threedimensional graphs showing antimicrobial activity (\% killing) of peptides from thrombin (THRB), FIX, FX, plasminogen (PLMN), protein $\mathrm{C}$ (PROC), ApoA (APOA), HABP2, granzyme B (GRAB) and $\mathrm{H}$ (GRAH), kallikreins 5, 8 and 10 (KLK5, KLK8, KLK10) as well as the negative controls FXI, C1r and kallikrein 9 (KLK9). Antimicrobial activity was assessed using viable count analysis in $0.15 \mathrm{M} \mathrm{NaCl}, 10 \mathrm{~mm}$ Tris, pH 7.4, alone (left) or in presence of $20 \%$ human plasma (right). b Inhibitory effects on NO production by RAW264.7 macrophage cells stimulated by LPS were evaluated. Cells were stimulated with LPS from E. coli $(10 \mathrm{ng} / \mathrm{ml})$, followed by treatment with the indicated peptides. Color coding illustrates the product of net charge and $\mu$ Hrel. c S1-derived HDPs significantly increase survival in LPS-induced shock. Mice were inject- ed with LPS, followed by intraperitoneal administration of the indicated peptides $(500 \mu \mathrm{g})$. Survival was followed for 7 days. ( $\mathrm{n}=10$ for controls, $\mathrm{n}=10$ for peptide-treated animals except for THRB where $n=7, p<0.001$ ). The graph for the FXI peptide overlaps with the control (\#). d As in c, but the indicated cytokines were analyzed in blood after $20 \mathrm{~h}(\mathrm{n}=11$ for controls, $\mathrm{n}=$ 11 for treated animals except for THRB where $n=6) .{ }^{*} p<0.05$; ${ }^{* *} \mathrm{p}<0.01{ }^{* * *} \mathrm{p}<0.001$, Mann-Whitney U test. e Upper two rows: histochemical analysis shows marked attenuation of inflammatory changes in lungs treated by the indicated peptides $20 \mathrm{~h}$ after LPS injection (a representative lung section is shown). Lower row: lungs were analyzed by scanning electron microscopy. Treatment with the HDPs blocked leakage of proteins and erythrocytes (a representative lung section is shown). 


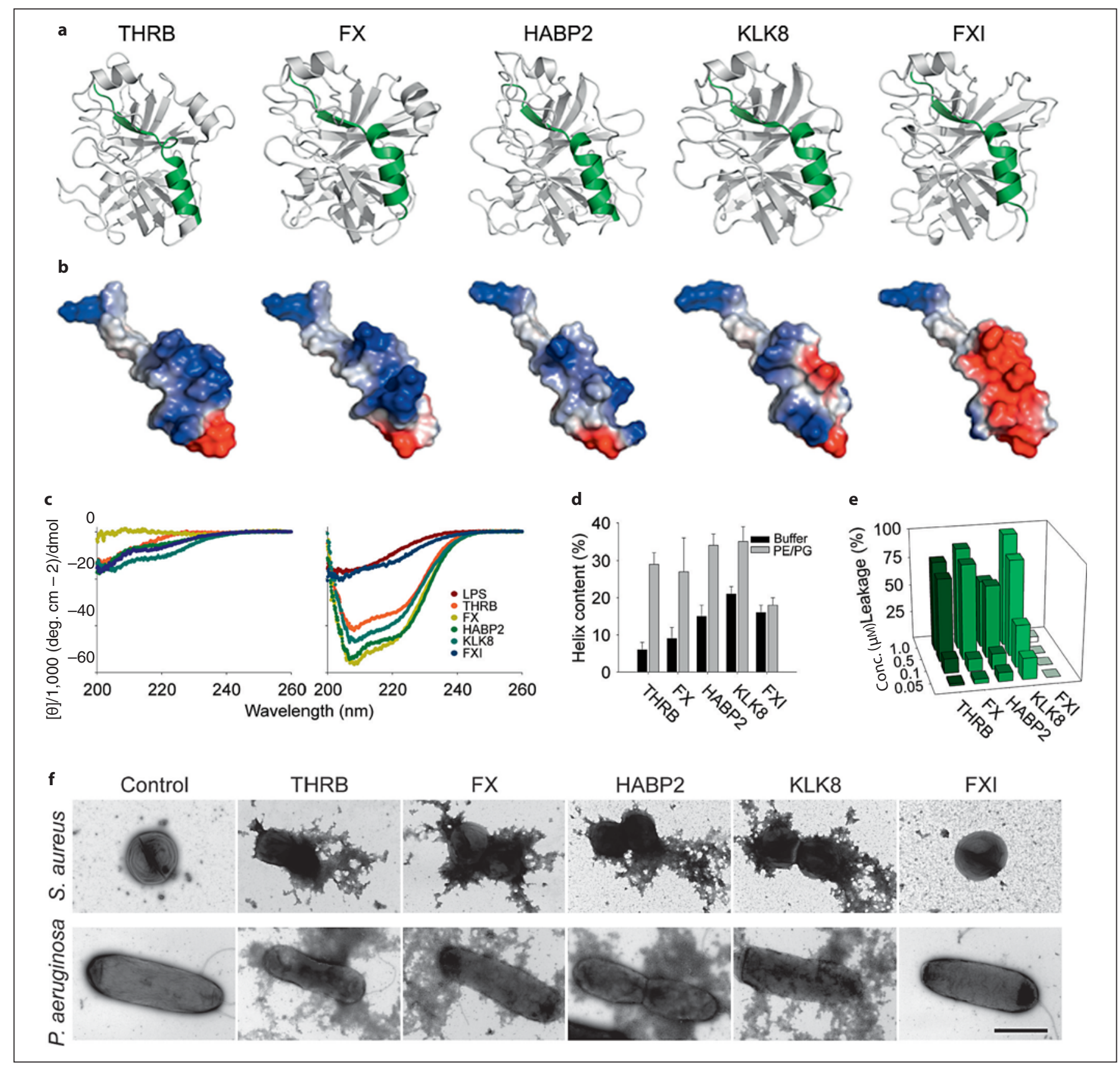

Fig. 5. Structural modeling and biophysical studies. a Three-dimensional models of thrombin (THRB), FX, HABP2, kallikrein 8 (KLK8) and FXI. Crystal structures with PDB codes 1C5L, 1HCG and 3BG8 were used for FII, FX and FXI to generate the figures, respectively. No crystal structures were available for human HABP2 and KLK8, and models from ModBase were used to generate the figures (http://modbase.compbio.ucsf.edu). b Surface representation of the 20-mer sequence (complying with the pattern sequence) illustrating the above peptides. Red color shows negative charge, blue color shows positive charge. The figure was generated by displaying only the region corresponding to the 20 -mer sequence from the above models of the whole proteins. c Circular dichroism spectra of the indicated peptides in $10 \mathrm{mM}$ Tris, $\mathrm{pH} 7.4$, in absence (left panel) or presence of E. coli LPS (right panel). The peptides assumed an unordered conformation in absence of LPS. d Helical content of the indicated peptides in Tris buffer or in presence of negatively charged liposomes (DOPE/DOPG; PE/PG). e Effects of the indicated peptides on liposome leakage. The membrane-permeabilizing effect was recorded by measuring fluorescence release of carboxyfluorescein from PA (negatively charged) liposomes. The experiments were performed in $10 \mathrm{mM}$ Tris buffer. Color coding as in figure 4. Values represent means of triplicate samples. $\mathbf{f}$ Electron microscopy analysis of effects of S1 HDPs. $P$. aeruginosa and $S$. aureus bacteria were incubated for $2 \mathrm{~h}$ at $37^{\circ} \mathrm{C}$ with $30 \mu \mathrm{M}$ of the indicated peptides and analyzed by transmission electron microscopy. Scale bar $=1 \mu \mathrm{m}$. Control = Buffer control. 
Table 1. C-terminal fragments of S1 peptidases

\begin{tabular}{|c|c|c|}
\hline Protein & C-terminal fragments & Comments \\
\hline Thrombin & 96 aa, 18 aа & released by neutrophil elastase, host-defense peptides [9] \\
\hline FX & 104 aa & released by plasmin [25] \\
\hline FIX & 98 aa & released by plasmin $[24]$ \\
\hline HABP2 & $\sim 8 \mathrm{kDa}$ & formed by autoproteolysis, up-regulated by LPS [29] \\
\hline Cathepsin G & 3,064 Da, RVSSFLPWIRTT... & antimicrobial, found in granule extracts [27] \\
\hline Kallikrein 8 & not determined & up-regulated in skin inflammation [34] \\
\hline
\end{tabular}

seems to be associated with not only a high net charge and $\mu \mathrm{Hrel}$ (fig. 3b, c), but also the ability to form a helix-stabilizing N-cap motif of the C-terminal helix. For example, the side chain of $\mathrm{H} 230$ in thrombin (H7 in KYG20) makes a hydrogen bond to the backbone amide three residues downstream (R233 or R10). Most of the active peptides have an amino acid type that allows $\mathrm{N}$-cap formation in position 7, notably Asn or Gln, as in the case of the peptides of HABP2 and kallikrein 8.

\section{Discussion}

Taken together, the present results uncover previously unknown structure-function relationships of C-terminal sequences of serine proteases and suggest novel important innate immune functions for peptides of several proteases present in blood and epithelia. Serine proteases of the S1 family have maintained a common structure over an evolutionary span of more than one billion years, and evolved a variety of substrate specificities and diverse biological roles involving digestion and degradation, blood clotting, fibrinolysis and epithelial homeostasis [19]. Of importance is the observation that the C-terminal function of the sequence in the protease domain has a dominant role in evolutionary decisions, accounting for S1 functional diversity, and containing critical information governing interactions of S1 proteins with substrates and also modulating enzyme activity [19]. At first sight, it may thus be argued that the current findings represent a parallel phenomenon, illustrating a mere structural and functional overlap between HDPs and sequence-encoded properties needed for $\mathrm{S} 1$ substrate recognition, and not as proposed here, defining novel functional roles for $\mathrm{S} 1 \mathrm{pep}-$ tides. As summarized in table 1 , however, evidence is mounting speaking in favor of the latter possibility. Thus, in addition to previously identified thrombin-derived Cterminal HDPs, additional findings on the plasmin-mediated release of similar fragments of FX and FIX [24, 25] as well as neutrophil elastase-generated C-terminal regions of plasminogen [26] lend further support to the concept. Indeed, similar to previous results with HDPs of thrombin [9], FX-derived peptides of approximately 10 $\mathrm{kDa}$, generated after subjection to neutrophil elastase, also exert antimicrobial activities (in preparation). Furthermore, cathepsin G-related C-terminal peptides (exerting antimicrobial activity, and encompassing the 20 aa sequence described here) [27], as well as C-terminal peptides of HABP2 (of about $8 \mathrm{kDa}$ ) [28] have indeed been identified. Although the exact role of the latter peptidase is not clarified, it is notable that LPS induces HABP2 expression in endothelial cells in vivo and in vitro [29]. Finally, neutrophil elastase degrades protein $\mathrm{C}$, generating low molecular weight fragments $(<14 \mathrm{kDa})$ [30]. Although no information is available on the identity of these peptides, it is noteworthy that activated protein C, currently approved for sepsis treatment, not only targets coagulation, but also exerts significant anti-inflammatory effects [31] and inhibits LPS-mediated lung injury [32].

From an evolutionary and functional point of view, it may be argued that a coherent (and parallel) evolution of substrate recognition of S1 sequences (situated in the holoprotein), as well as a host defense function (of released HDPs), is both logical and energetically cost-effective, minimizing the need for de novo synthesis of HDPs, and providing a fast, localized and protease-dependent innate immune response. The existence of such general serineprotease networks induced in response to a 'danger' situation, and characterized by multiple cross-activations, generating a primary pro-inflammatory enzyme-mediated cascade (as illustrated by the coagulation and kallikrein systems), and a secondary, anti-inflammatory re- 
sponse mediated by HDPs, is elegantly illustrated by thrombin and the coagulation system [9]. Here, selective and highly localized proteolytic activations mediate initial defense functions (including PAR activations and fibrin clot formation) [33], followed by the generation of HDPs by the subsequent proteolytic action of neutrophil elastase, cathepsin $\mathrm{G}$ and possibly other enzymes such as plasmin (table 1). In this context it is highly interesting that kallikreins (such as kallikreins 5 and 8) are upregulated and activated during inflammation in skin [34], but it remains to be investigated whether further proteolysis releases anti-inflammatory kallikrein-derived HDPs in skin. It is also notable, and supporting the above reasoning on a function of $S 1$ peptides in innate immunity, that the major HDPs identified in this work are derived from enzymes involved in coagulation and epithelial homeostasis, of relevance for host defense. Clearly, further work is mandated in order to define the physiological signifi- cance and temporospatial generation of this class of S1derived fragments. Nevertheless, the present results provide new insights into the structure-activity relationships of C-terminal regions of S1 peptidases and propose fundamental and novel roles for certain S1 peptidases in host defense.

\section{Acknowledgments}

This work was supported by grants from the Swedish Research Council (projects 521-2009-3378, 7480 and 621-2003-4022), the Royal Physiographic Society in Lund, the Welander-Finsen, Crafoord, Österlund and Kock Foundations, Marianne and Marcus Wallenberg Foundation, XImmune AB, and The Swedish Government Funds for Clinical Research (ALF). We wish to thank Ms. Maria Baumgarten and Ms. Lotta Wahlberg for expert technical assistance. The help of Ms. Rita Wallén, Department of Cell and Organism Biology, with electron microscopy is gratefully acknowledged.

\section{References}

$\checkmark 1$ Lehrer RI, Ganz T: Cathelicidins: a family of endogenous antimicrobial peptides. Curr Opin Hematol 2002;9:18-22.

2 Harder J, Gläser R, Schröder JM: Review: human antimicrobial proteins effectors of innate immunity. J Endotoxin Res 2007;13: 317-338.

-3 Zasloff M: Antimicrobial peptides of multicellular organisms. Nature 2002;415:389395.

-4 Tossi A, Sandri L, Giangaspero A: Amphipathic, $\alpha$-helical antimicrobial peptides. Biopolymers 2000;55:4-30.

$\checkmark 5$ Yount NY, Bayer AS, Xiong YQ, Yeaman MR: Advances in antimicrobial peptide immunobiology. Biopolymers 2006;84:435458.

6 Zanetti M: Cathelicidins, multifunctional peptides of the innate immunity. J Leukoc Biol 2004;75:39-48.

7 Elsbach P: What is the real role of antimicrobial polypeptides that can mediate several other inflammatory responses? J Clin Invest 2003;111:1643-1645.

-8 Ganz T: Defensins: antimicrobial peptides of innate immunity. Nat Rev Immunol 2003;3: 710-720.

-9 Papareddy P, Rydengård V, Pasupuleti M, Walse B, Mörgelin M, Chalupka A, Malmsten M, Schmidtchen A: Proteolysis of human thrombin generates novel host defense peptides. PLoS Pathog 2010;6:e1000857.

$\checkmark 10$ Loof TG, Schmidt O, Herwald H, Theopold $\mathrm{U}$ : Coagulation systems of invertebrates and vertebrates and their roles in innate immunity: the same side of two coins? J Innate Immun 2011;3:34-40.
11 Doolittle RF: Coagulation in vertebrates with a focus on evolution and inflammation. J Innate Immun 2011;3:9-16.

12 Yeaman MR, Yount NY: Unifying themes in host defence effector polypeptides. Nat Rev Microbiol 2007;5:727-740.

$>13$ de Castro E, Sigrist CJ, Gattiker A, Bulliard V, Langendijk-Genevaux PS, Gasteiger E, Bairoch A, Hulo N: Scanprosite: detection of prosite signature matches and prorule-associated functional and structural residues in proteins. Nucleic Acids Res 2006;34:W362W365.

14 Schmidtchen A, Frick IM, Andersson E, Tapper H, Björck L: Proteinases of common pathogenic bacteria degrade and inactivate the antibacterial peptide ll-37. Mol Microbiol 2002;46:157-168.

15 Andersson E, Rydengård V, Sonesson A, Mörgelin M, Björck L, Schmidtchen A: Antimicrobial activities of heparin-binding peptides. Eur J Biochem 2004;271:1219-1226.

16 Lehrer RI, Rosenman M, Harwig SS, Jackson R, Eisenhauer P: Ultrasensitive assays for endogenous antimicrobial polypeptides. J Immunol Methods 1991;137:167-173.

17 Pollock JS, Forstermann U, Mitchell JA, Warner TD, Schmidt HH, Nakane M, Murad F: Purification and characterization of particulate endothelium-derived relaxing factor synthase from cultured and native bovine aortic endothelial cells. Proc Natl Acad Sci USA 1991;88:10480-10484.
8 Taboureau O: Methods for building quantitative structure-activity relationship (QSAR) descriptors and predictive models for computer-aided design of antimicrobial peptides. Methods Mol Biol 2010;618:77-86.

19 Krem MM, Rose T, Di Cera E: The C-terminal sequence encodes function in serine proteases. J Biol Chem 1999;274:2806328066.

20 Medzhitov R, Preston-Hurlburt P, Janeway CA Jr: A human homologue of the drosophila Toll protein signals activation of adaptive immunity. Nature 1997;388:394-397.

21 Kankkunen P, Teirila L, Rintahaka J, Alenius $H$, Wolff $H$, Matikainen S: $(1,3)-\beta$-glucans activate both dectin-1 and NLRP3 inflammasome in human macrophages. J Immunol 2010;184:6335-6342.

22 Pasupuleti M, Walse B, Svensson B, Malmsten M, Schmidtchen A: Rational design of antimicrobial C3a analogues with enhanced effects against staphylococci using an integrated structure and function-based approach. Biochemistry 2008;47:9057-9070.

23 Zelezetsky I, Tossi A: $\alpha$-Helical antimicrobial peptides-using a sequence template to guide structure-activity relationship studies. Biochim Biophys Acta 2006; 1758:14361449.

24 Samis JA, Ramsey GD, Walker JB, Nesheim $\mathrm{ME}$, Giles AR: Proteolytic processing of human coagulation factor IX by plasmin. Blood 2000;95:943-951.

25 Pryzdial EL, Lavigne N, Dupuis N, Kessler GE: Plasmin converts factor $\mathrm{X}$ from coagulation zymogen to fibrinolysis cofactor. J Biol Chem 1999;274:8500-8505. 
26 Warejcka DJ, Twining SS: Specific conformational changes of plasminogen induced by chloride ions, 6 -aminohexanoic acid and benzamidine, but not the overall openness of plasminogen regulate, production of biologically active angiostatins. Biochem J 2005; 392:703-712.

27 Miyasaki KT, Qu XD, Harwig SS, Cho Y, Lehrer RI: Identification of CG-1, a natural peptide antibiotic derived from human neutrophil cathepsin G. Adv Dent Res 1995;9: 63-66.
28 Choi-Miura NH, Takahashi K, Yoda M, Saito K, Mazda T, Tomita M: Proteolytic activation and inactivation of the serine protease activity of plasma hyaluronan binding protein. Biol Pharm Bull 2001;24:448-452.

29 Mambetsariev N, Mirzapoiazova T, Mambetsariev B, Sammani S, Lennon FE, Garcia JG, Singleton PA: Hyaluronic acid binding protein 2 is a novel regulator of vascular integrity. Arterioscler Thromb Vasc Biol 2010; 30:483-490.

30 Eckle I, Seitz R, Egbring R, Kolb G, Havemann K: Protein $C$ degradation in vitro by neutrophil elastase. Biol Chem Hoppe Seyler 1991;372:1007-1013.

- 31 Danese S, Vetrano S, Zhang L, Poplis VA, Castellino FJ: The protein $\mathrm{C}$ pathway in tissue inflammation and injury: pathogenic role and therapeutic implications. Blood 2010;115:1121-1130.
32 Murakami K, Okajima K, Uchiba M, Johno M, Nakagaki T, Okabe H, Takatsuki K: Activated protein $\mathrm{C}$ attenuates endotoxin-induced pulmonary vascular injury by inhibiting activated leukocytes in rats. Blood 1996; 87:642-647.

33 Bode W: The structure of thrombin: A janusheaded proteinase. Semin Thromb Hemost 2006;32(suppl 1):16-31.

34 Ovaere P, Lippens S, Vandenabeele P, Declercq W: The emerging roles of serine protease cascades in the epidermis. Trends Biochem Sci 2009;34:453-463. 